\title{
THE CONCEPT OF REFLEXIVE MANAGEMENT OF CONSUMER DEMAND
}

\author{
Maryna MAVRINA ${ }^{1}$ \\ Pryazovskyi State Technical University, Ukraine
}

\begin{abstract}
Development of theoretical approaches of demand management is conducted from the moment of awareness of the importance of this concept. Many models of individual consumers were developed. However, to predict the reaction of consumers to the commercial policy of the enterprise, exact methods do not exist yet because the available ones are mostly empirical in nature. Models of behaviour often do not provide the expected result because they use an erroneous approach to the analysis of the mechanism of demand formation. The subject of the research is the theoretical and methodological basis, methods of assessment, and reflexive management of consumer demand of commercial enterprises. The purpose of the paper is developing a concept of reflexive management of consumer demand. To achieve the research goal, the following tasks are set and solved: to substantiate the theoretical and methodological foundations of reflexive consumer management, to analyse existing approaches to the modelling of consumer behaviour; to improve the model of consumer behaviour; to develop a concept of reflexive management of consumer behaviour. Methodology. In the paper, we use such methods and approaches to research as: reflexive approach (phenomenological method), behavioural economic theory, marketing approach, abstract-logical analysis, analysis of theoretical approaches to the modelling of consumer behaviour. Results. Modern approaches to modelling of consumer behaviour are mostly empirical in nature and have shortcomings of general models. In them, there is no description of specific situations of the purchase of goods. They cannot be quantified. Therefore, they cannot be practical models. But they have a weighty advantage in a comprehensive look at motivated purchases, what makes it possible to evaluate the relevance of individual variables and to understand the fundamental processes of consumer behaviour. It makes possible to identify the variables necessary for the research, gives rise to the construction of a hypothesis. Practical implications and originality of the results obtained are the development of the concept of reflexive management of consumer demand, which will allow taking into account personal preferences of potential customers in the activity of a commercial enterprise. The concept envisages the use in the practice of targeted impacts on consumer information channels and promotes competitive advantage. The model of the process of consumer acceptance of the purchase decision is improved, taking into account the personal preferences of the target consumer. The model of the process of consumer acceptance of the purchase decision is improved. All this allows us to determine the key steps in the decision-making process by the consumer with the aim of developing a complex of reflexive influences.
\end{abstract}

Key words: consumer demand, consumer behaviour, model of consumer behaviour, demand management, marketing, reflexive management.

JEL Classification: B1, D11, D12, M31

\section{1. Введение}

Спрос преАставмяет собой амя коммерческого преАприятия гмавный объект конкурентной борьбы и как результат эффективной работы, выражающийся в конкурентоспособности. Сама же конкурентоспособность понятие относительной, т.к. показывает способность предприятия созАавать востребованный продукт по сравнению с аналогами в опредеАённых территориальных границах, будь то регион, страна или целый континент. Так же на неё оказывает влияние потенциац рынка, стоимость входа в него, УРовень ОАНорОАНости и т.А.

Развитие теоретических подходов управления спросом ведутся с момента осознания представителями экономической науки важности Аанного понятия. С усложнением теоретических подхоАов к анализу экономического поведения с точки зрения психологической природы человека было разработано множество моделей инАивидуальных потребитемей. ОАнако Амя прогнозирования

Corresponding author:

${ }^{1}$ Department of Finance and Banking, Pryazovskyi State Technical University.

E-mail: Mavinamaryna@gmail.com 
реакции потребителей на коммерческую политику преАприятия в условиях не ценовой конкуренции точных методов пока не существует, потому что имеющиеся носят преимущественно эмпирический характер. Так же необходимо признать, что используемые модели поведения часто не обеспечивают ожидаемый результат по причине ошибочного подхода к анализу механизма формирования спроса как такового.

Целью исслеАования является разработка концепции рефмексивного управления потребительским спросом. Аля Аостижения цели исследования поставлены и решены такие задачи: обосновать теоретико-методологические основы рефлексивного управления потребительским спросом; выявить и проанализировать существующие поАходы к модемированию потребительского поведения; усовершенствовать модель потребительского поведения; разработать концептуальные положения рефлексивного управления поведением потребителей.

В работе использованы такие методы и подходы к исследованию: рефлексивный подход (феноменологический метоА), поведенческая экономическая теория, маркетинговый поАхоА, абстрактно-логический анализ использован при исследовании теоретико-методологических основ Управления взаимодействиями, анализе теоретических ПоАходов к моделированию потребительского поведения, разработке концепции рефмексивного управления поведением потребитемя, при теоретическом обобщении и формумировании выводов.

\section{2. Сущность рефмексивного управкения спросом}

Управление взаимодействиями в коммерческом преАприятии заключается в созАании стратегии нацеленной на УАовметворение потребностей существующих и потенциальных клиентов. Поэтому спрос является основополагающим фактором работы преАприятия и одной из главных переменных рынка наряду с преАложением и ценой (Kotler, 1984). Т.к. поА спросом скрываются желания, готовность и возможность экономических субъектов приобретать необходимые Аля них товары (ускуги), то на первый план исследований выходят механизмы принятия потребительских решений или модели поведения, Аля выделения перспективных направлений возАействий с целью получения конкурентного преимущества и Аальнейшего финансового роста преАприятия как экономического агента.

Ориентация на нужды и потребности целевых клиентов, подкрепленная аАекватной системой управмения хозяйственной Аеятельностью, нацеленной на созАание потребительской УАовлетворённости в качестве основы Амя Аостижения поставценных цемей преАприятия, явцяется гарантией успеха.
Таким образом, понятие «взаимодействие» явцяется важной составцяющей Аеятельности преАприятия, без учёта которой невозможна эффективная работа в условиях рынка.

Вопросам теории рефлексии УАеляют внимание большое число исследователей, среди которых В.А. Аефевр, В.Е. Аепский, Г.П. ЩеАровицкий, Е.Н. Емемьянов, А.В. Карпов, А.С. Шаров, И.Н. Семёнов, С.Ю. Степанова, Г.М. Андреева, А.А. Бодалёв, И.С. Ааденко, А.В. Россохин и Ар.

Впервые рефлексивное управление (РУ), как научное понятие ввёл советский и американский психомог и математик, создатель концепции рефлексивных игр В.А. Аефевр. Он преАставиц математический поАхоА К социальной психологии в «теории рефмексии». Описал человеческое поведение в виде уравнений, параметрами которых выступают воздействие мира на субъект, субъективный образ этого воздействия и интенция самого субъекта (Lefevre, 2003). Рефлексивное управление В.А. Аефевр определяет как процесс переАачи оснований Аля принятия преАопределенного решения (Lefevre, 2009). Он истолковывает РУ как особый способ получения информации, о взаимодействующих субъектах, исследуя рефлексивную систему, в которой важная роль отвоАится занимаемым персонажами рангам рефлексии, плацдарму, операторам осознания.

Например, рефлексия первого ранга - это собственные преАставмения субъекта о внешнем мире. Второго ранга - преАставления о себе и Аругом персонаже. Третий ранг - на уровне второго ранга имея представмения о взгляаах Аругих персонажей. По своей сути они соответствуют процессам осознания окружающей реальности субъектами исследуемой рефлексирующей системы. Теоретическое количество рангов не ограничено. Ранги рефмексии изображены на рис. 1-3.
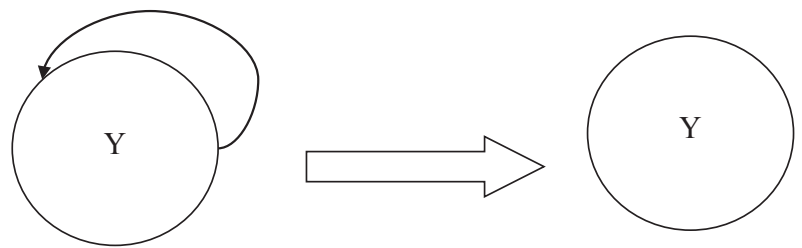

Рис. 1. Первый ранг рефмексии

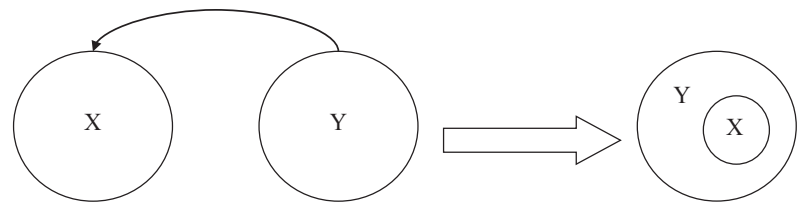

Рис. 2. Второй ранг рефмексии

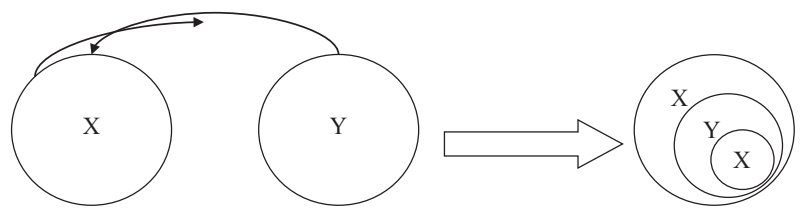

Рис. 3. Третий ранг рефмексии 
Из-за сложности графического и естественного изображения рефлексивных процессов В.А. Аефевр разработал специфический аналитический аппарат со специальным «амгебраическим языком» в виде рефлексирующей системы. Место осуществления РУ является некий условный «пиацАарм» Т, на котором Аействуют персонажи, например X,Y. Учитывается момент времени «осознания» ситуации ti. B процессе осознания происходит понимание или «физической реальности», или картины происходящего вокруг. Как слеАствие, возникают элементы виАа Тх и Тхх соответственно.

Амя нагмядности, изобразим процесс взаимодействий персонажей показанных на рисунках 1-3. В момент $t_{0}$ у субъекта Y нет внутренних картин (рис.1). Рефлексивная система имеет виА пиацдарма Т. Рефлексивная система на рис. 2 в момент времени $t_{1}$ принимает виА суммы (1) и состоит из плацдарма Т и картины пиацдарма переА Y:

$$
\Omega_{1}=\mathrm{T}+\mathrm{Ty} .
$$

Рис. 2 соответствует многочиен (2):

$$
\Omega_{2}=\mathrm{T}+\mathrm{Ty}+(\mathrm{T}+\mathrm{Ty}) \mathrm{x}=\mathrm{T}+\mathrm{Ty}+\mathrm{Tx}+\mathrm{Tyx} .
$$

Аля фиксации процесса осознания используется специальный формализм - оператор осознания ( $\omega)$. Он является формальным способом изображения перехода рефлексивной системы от одного состояния в Аругое, т.е. преАставляет собой схематичное представление естественного понимания рефлексии как таковой. А само состояние рефмексирующей системы приобретает виА специфического многочмена $\Omega=\mathrm{T} \omega$.

Выразим на алгебраическом языке процессы перехода картин на рис. 2 в рис. 3 и т.А. Аля этого плацАарм умножим на оператор осознания $1+y$ и получим результат в виде многочиена (3):

$$
\Omega_{1}=\mathrm{T}(1+\mathrm{y})=\mathrm{T}+\mathrm{Ty} .
$$

Аля Аахьнейших превращений полученный многочиен $\Omega_{1}$ снова умножаем на оператор осознания, который принимает вид в Аанном случае, $\Omega=1+$ х и получаем выражение (4) эквивалентное $(2)$ :

$$
\begin{aligned}
& \Omega_{2}=T(1+y)(1+x)=T+T y+(T+T y) x= \\
& =T+T y+T x+T y x .
\end{aligned}
$$

Следовательно, представленной графически процедуре осознания на рис. 1-3 соответствует амгебраическая операция умножения многочиенов $(1+y)$ $(1+x)$. Аанное осознание явцяется последовательным, но оно может быть и оАновременны, тогАа оператор осознания становится (5):

$$
\omega=1+y+x,
$$

Многочлен рефлексирующей системы примет виА выражения (6):

$$
\Omega_{\mathrm{n}}=\mathrm{T}(1+\mathrm{y}+\mathrm{x})^{\mathrm{n}} \text {, }
$$

Подобным изображением сложных типов социамьных взаимодействий, которые практически невыразимы естественным языком, В.А. Аефевр значительно расширия возможности их исслеАования Аля Аахьнейшего РУ (Lefevre, 2009).

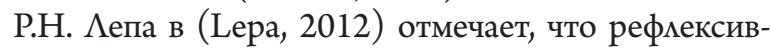
ное управление процессом принятия решения управмяемым субъектом происходит посреАством оказания воздействия на его психику. В этот процесс так же входит расчёт эффективности осуществленного воздействия. При этом Аля стороны, веАущей рефмексивное управление, важно не только отслеживать поведение конкурента и реагировать на его действия, но и упрежАать его намерения, периодически ввоАя в заблужАение относительно собственных намерений.

\section{2. ПоАХодЫ МодемироваНИЯ потребительского повеАения}

Значение изучения взаимодействий межАу коммерческим преАприятием и потребителем, которые Аействуют в постоянно изменяющихся условиях рынка, труано переоценить, т.к. от этого зависит спрос и сбыт создаваемого продукта и как слеАствие результат Аеятельности самого преАприятия. Знания модели поведения потребителя или размичных групп потребителей Аают непревзойдённое конкурентное преимущество виде перспективных направлений воздействий на клиентов Аля формирования надёжных взаимовыгодных отношений. ПреАставители экономической науки, начиная со времён зарождения классической школы и АО сегодняшнего Аня, продолжают исследовать разные аспекты теории поведения потребителя: факторы разного характера, влияющие на поведение, непосреАственный процесс принятия решения о покупке, рациональность и иррационацьность выбора, учёт неопределённости, недостаток информации.

Первые идеи экономического поведения мюАей в качестве потребителей появились в эпоху нерегулируемых рыночных отношений. А именно, в классической политической экономии и связаны с именем Адама Смита (1723-1790) - английского ученого-экономиста конца XVIII в. В своём величайшем труде «Исследование о природе и причинах богатства народов» 1776 г. опубликования, потребитель впервые выступает объектом исследования. Модель «Homo Economicus» описывает частный случай потребительского поведения, основанного на скмонности к обмену и стремлениях к кучшей жизни, с присущим АюАям эгоизмом (Yadgarov, 2009). Таким образом, первые попытки представления и объяснения поведения человека в рамках экономической науки связаны с именем А. Смита.

Маржинализм стал исторически первой экономической школой, заинтересовавшейся проблемой потребительского выбора. САелав принцип субъ- 
ективности ценности благ основой анамиза поведения, тем самым заложил фундамент математического моделирования экономического поведения. ПослеАователи этого направления использовали данные наблюдений, идеи философии и этики. Именно маржинализму мы обязаны появмением понятия полезности и ввеАением в обиход преАельной полезности в качестве инструмента анализа поведения потребитемя. ОАнако, маржинализм (например, Австрийская школа - как его ярчайший преАставитель) абсолютизировац принцип субъективности, и поэтому его преАставители не смогли объективного характера экономических взаимосвязей и взаимозависимостей. Объективность таких экономических величин как спрос и цена, которая присутствоваца в учении киассической экономической школы, была потеряна маржиналистами и вновь появилась в неоклассическом подходе к экономике (в частности, у А. Маршамла). Неоклассика смогла произвести синтез Авух противоречащих Аруг Аругу подходов. Синтез этот основан на том факте, что в экономике Аействует очень много субъектов, и, хотя поведение каждого основано на субъективных принципах, но общее поведение можно считать вполне объективным, из-за Аействия закона больших чисел.

Аамьнейшее развитие теории поведения потребителя Аолгое время происходило в рамках неоклассической теории, которая, с оАной стороны, смогла более глубоко понять смысл полезности и разработать теорию потребительского выбора, а с Аругой - применила теорию полезности к проблемам потребительского выбора в разных ситуациях, созАав теорию межвременных преАпочтений и теорию рисковых преАпочтений потребителя.

ОАнако экономическая практика показала наличие У неокиассического подхода некоторых недостатков, в частности, наличие возможности манипулирования спросом потребителей и субъективность формирования спроса и цены в некоторых ситуациях. Поэтому возник Маркетинг, имеющий свою теорию поведения потребителя, а также методики управления этим поведением.

ОАновременно подрывать базис неоклассической экономической теории стала психология, выяснившая, что человек веАет себя полностью разумно мишь в некоторых ситуациях. Точнее тогАа, когАа не может применить иные механизмы принятия решений, связанные с подражанием и использованием типовых механизмов поведения. Более того, исследования психологов показали, что Ааже если поведение формируется рационально, оно не обязательно Аолжно быть оптимацьным, так как человеку трудно точно оценить все варианты выбора, поэтому в послеАствие, если возникнет сходная ситуация, сделанный выбор корректируется. Т.е. человек не сразу делает оптимацьный выбор, а действует методом проб и ошибок (Yadgarov, 2009).
Первым учёным, обратившимся к психологии Амя объяснения причин осуществления индивидуального потребительского решения, быц Аж. Кейнс. Он обосновац необходимость использования психологических факторов Аля прогноза повеАения индивида как экономического агента. В Аальнейшем экономическая психология приобретает статус самостоятельной области знания благодаря работам Ж.Г. ТарАа.

Ао второй половины XX в. модель поведения строилась на принципе рационального поведения, что критикует и преАлагает новый поАхоА ограниченной рациональности Г. Саймон. Аанная концепция приобретает широкое признание и применение к разАичным виАам экономического повеАения.

В конце 1960-х гг. появмяются первые учебники по потребительскому поведению, наиболее важным из них становится работа Аж. ЭнАжела, А. Комлата и Р. Блэкуэмиа.

Заслуживает внимания модель Говарда-Шета, описывающая приобретение часто покупаемого продукта, как непрерывный процесс, характеризующийся подъёмами и спадами в поиске информации, аналогичным циклическим колебаниям в экономике.

ОАнако приходится признать, что имеющиеся в настоящее время поАХоАЫ К моАелированию потребительского поведения носят преимущественно эмпирический характер и обладают недостатками общих моделей. В них нет описания конкретных покупательских ситуаций настолько подробно, чтобы быть практическими модемями, и их нельзя выразить количественно. Несмотря на это анализируемые поАходы имеют весомое преимущество во всестороннем взгляде на мотивированные покупки, что позволяет оценить релевантность отАельных переменных и тем самым кучше понять фунааментальные процессы поведения потребителей. Позволяет идентифицировать необходимые Аля исследования переменные, Ааёт старт Аля построения гипотезы и точку отсчёта Аля интерпретации результатов экспериментов.

\section{3. Концепция рефмексивного управмения потребительским спросом}

Внешняя среАа Аля потребителя преАставляет собой совокупность экономических субъектов, которые оказывают на него вмияние посреАством информационных потоков. Её совокупная информация преАставлена в виде социальных и культурных устоев общества, законодательных норм и ограничений, уровня развития и использования НТП, экономической активности хозяйствующих субъектов. Весь этот поток информации формирует внутреннюю среду потребителя, а именно: мотивы и мичные предпочтения, которые направлены на удовлетворение возникающих потребностей Аля Аахьнейшего обеспечения бкагопомучия и преАсказуемости буду- 
щего. Таким образом, внешняя среда воздействует на модемь поведения и осуществления выбора потребителем. Аанный процесс преАставлен на рис. 4.

На рис. 4 мы виАим, что поА влиянием информационных потов субъектов внешней среды потребитель осуществляет выбор в пользу того или иного конкурирующего предприятия, используя при этом составляющие своей внутренней среАы. НепосреАственный процесс принятия решения основывается на потребностях покупатекей и факторах, опредемяющих модель их поведения. В митературе (Levy, 2013) выдемяют 3 типа таких процессов, это развёрнутый, ограниченный и по привычке. Первый присущ к покупкам с высокой вероятностью финансового, социального и физического рисков. Потребитель в этом случае глубоко вовлечён в процесс покупки, потому что ему необходимо уАовлетворить важную потребность или восполнить неАостающие знания о приобретаемом продукте. В этом случае продавец может оказать влияние на выбор потребитемя при предоставлении ему необходимой информации в выгодном Аля себя свете.

Ограниченный тип процесса принятия решения потребителем реализуется при условии умеренного риска во время приобретения того или иного виАа товара/услуги по причине наличия необходимой информации у покупатемя. Примером явмяется приобретение торговых марок, которые уже приобретались ранее и созАали о себе положительный опыт так же и импульсные покупки. ЗАесь способ вмияния на сознание потребитель можно реализовать с помощью грамотно разработанной презентации товаров/ ускуг в преАназначенных Аля этого зонах торгового пространства.

Привычный тип принятия решения тесно граничит с понятием покупательской мояльности к торговой марке, бренду или торговой точки. Из-за хронической нехватки времени усовременного потребителя формируется привязанность к опреАелённым по его Аичным критериям выбора торговым маркам или «избранным» магазинам. У продавца есть возможность привлечь большое количество мояльных потребителей посредством Удобства местоположения, преАложения широкого ассортимента, вознаграждения постоянных клиентов с помощью гибкой системы скидок и акций, предоставления высокого уровня сервиса, тем самым оказывая скрытое воздействие на повеАение целевой аудитории. В Аанной работе будет рассмотрен только третий тип принятия решения потребителем. В источнике (Levy, 2013) аля рынка продовольственных товаров такой тип принятия решения потребителем преАставлен в слеАующей послеАовательности Аействий: осознание потребности, поиск информации, оценка, выбор, выводы. Усовершенствуем и преАставим выдеменную послеАовательность действий потребителя в виде модели принятия решения (рис. 2).

В преАставленной на рис. 5 модели выделены главные этапы принятия потребителем решения с цемью преАложения комплекса рефлексивного воздействия на поведение потребитемя.

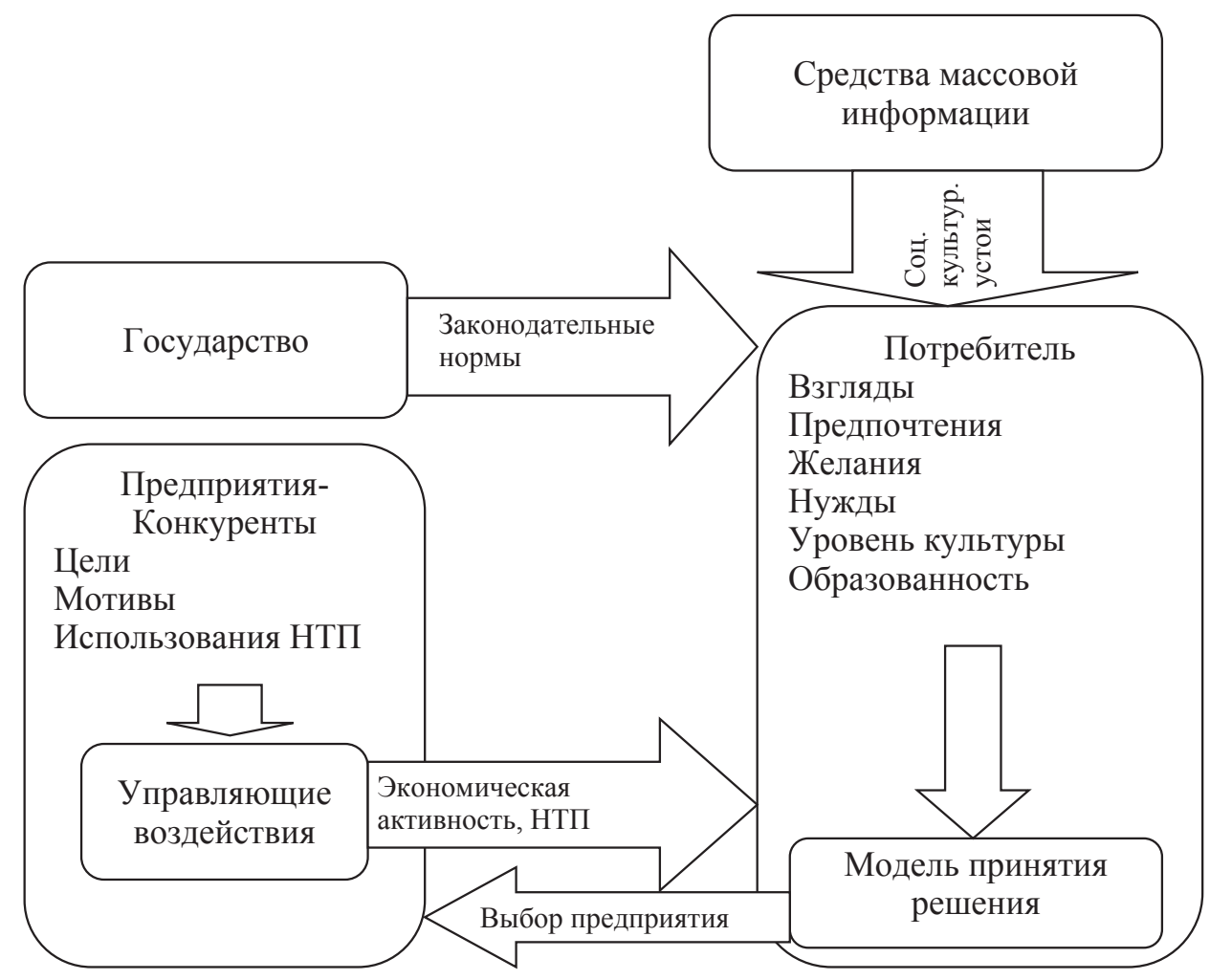

Рис. 4. Взаимодействие потребителя с внешней среАой 


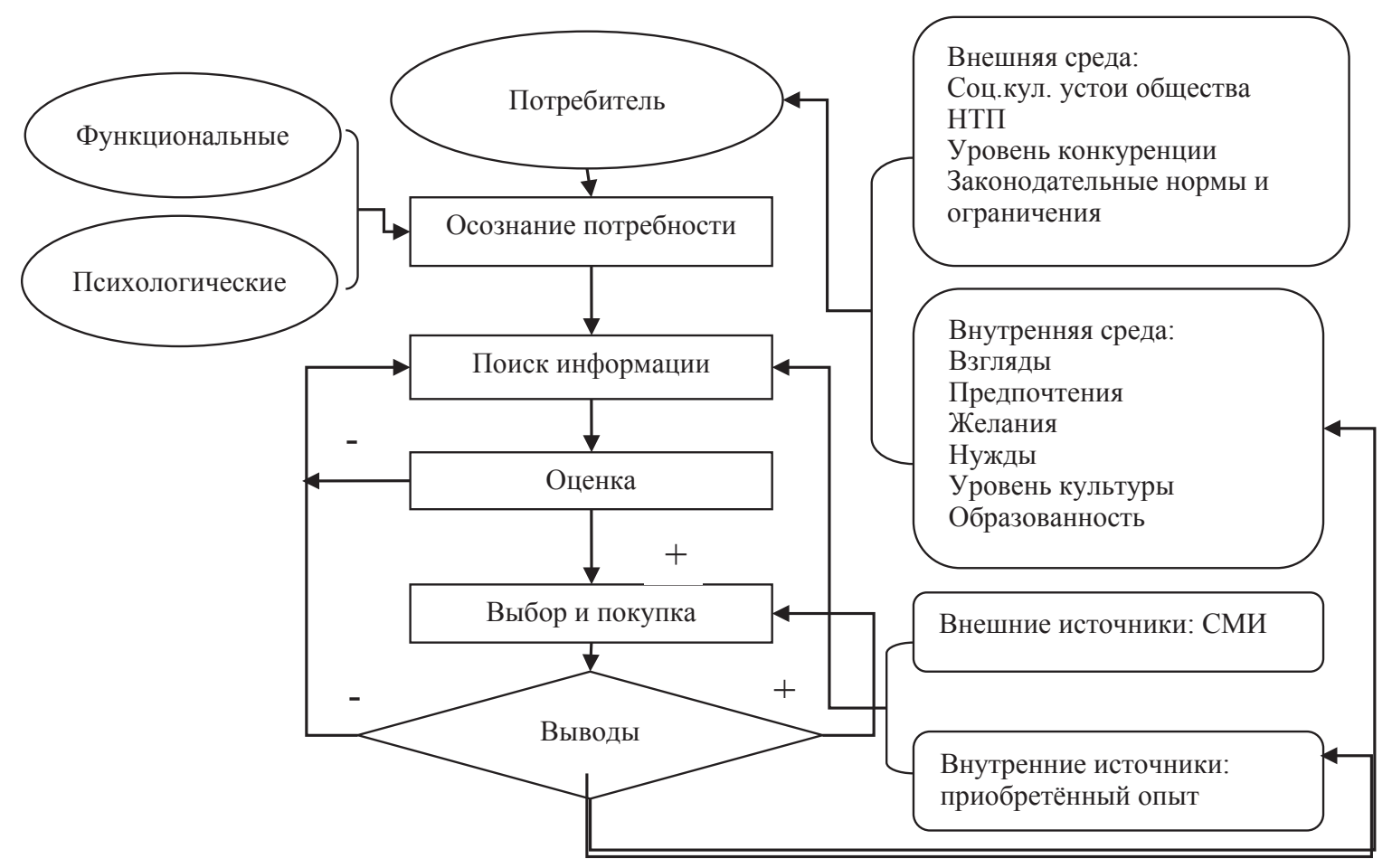

Рис. 5. Модель принятия потребительского решения

Амя разработки концепции рефмексивного управмения потребительским спросом подробно рассмотрим кажАый этап Амя выявмения возможности преАприятия воздействовать на процесс принятия потребителем решения о покупке товара/услуги. Отметим один важный факт: потребитель не обязательно проходит выделенные этапы по порядку. Возможно, он вначаме примет решение о покупке и только потом будет искать поАходящее место Аля осуществления покупки.

Осознание потребности представмяет собой начальную стадию процесса покупки. Различают Ава типа потребностей: функциональные и психологические. Первые ещё называют рациональными, потому что они напрямую связаны с физическими характеристиками продукта. К психологическим или эмоциональным потребностям относят стимулирование, вознаграждение, изучение новых тенденций, статус и власть. Возможность преАприятия оказывать влияние на процесс возникновения и осознания потребности у покупатемя ограничена маркетинговыми инструментами. Аополнительным инструментом может выступить рефлексивное воздействие на психологическую природу потребителя, несущее в себе информацию о наличии продукта и преимуществе приобретения его в конкретном месте в сравнении с преАприятиями-конкурентами.

Поиск информации осуществмяется в направлении необходимого продавца или товара/ускуги. Источники информации бывают Авух типов: внутренние и внешние. К внутренним относится прошлый опыт, внешним - рекламные средства, отзывы Аругих потребителей. При условии недостачи внутренний информации покупатель обращается за необходимыми Аанными к внешним источникам. Результатом выступает сформированный набор критериев мичных преАпочтений с разной степенью веса. Возможность рефмексивного воздействия можно реализовать через создание благоприятного Аля продавца информационного пространства, которое будет влиять на оба типа источников.

Оценка выбранных вариантов Амя потребитемя альтернативных товаров/ускуг и торговых преАприятий осуществмяется по принципу наибольшей привмекательности на основе его собственных предпочтений. В этом скучае рефлексивное воздействие со стороны продавца может быть эффективным, если в сознании у потребителя уже есть положительный опыт приобретения необходимых Аля уАовметворения собственных потребностей покупок у Аанного экономического субъекта.

Потребитель не всегАа имеет возможность приобрести выбранный им продукт по ряду причин: его может не быть в наличии, торговая точка может оказаться закрытой, не принимать к оплате платёжные карты и т.п. Поэтому только от преАприятий зависит, сможет ии клиент превратить положительную оценку необходимого Амя него товара в реальную покупку. ЗАесь важную роль играют заинтересованность индивиАа в приобретении, выработанный поАхоА продавца к разАичным группам кАиентов, гибкая система скидок и т.п. 


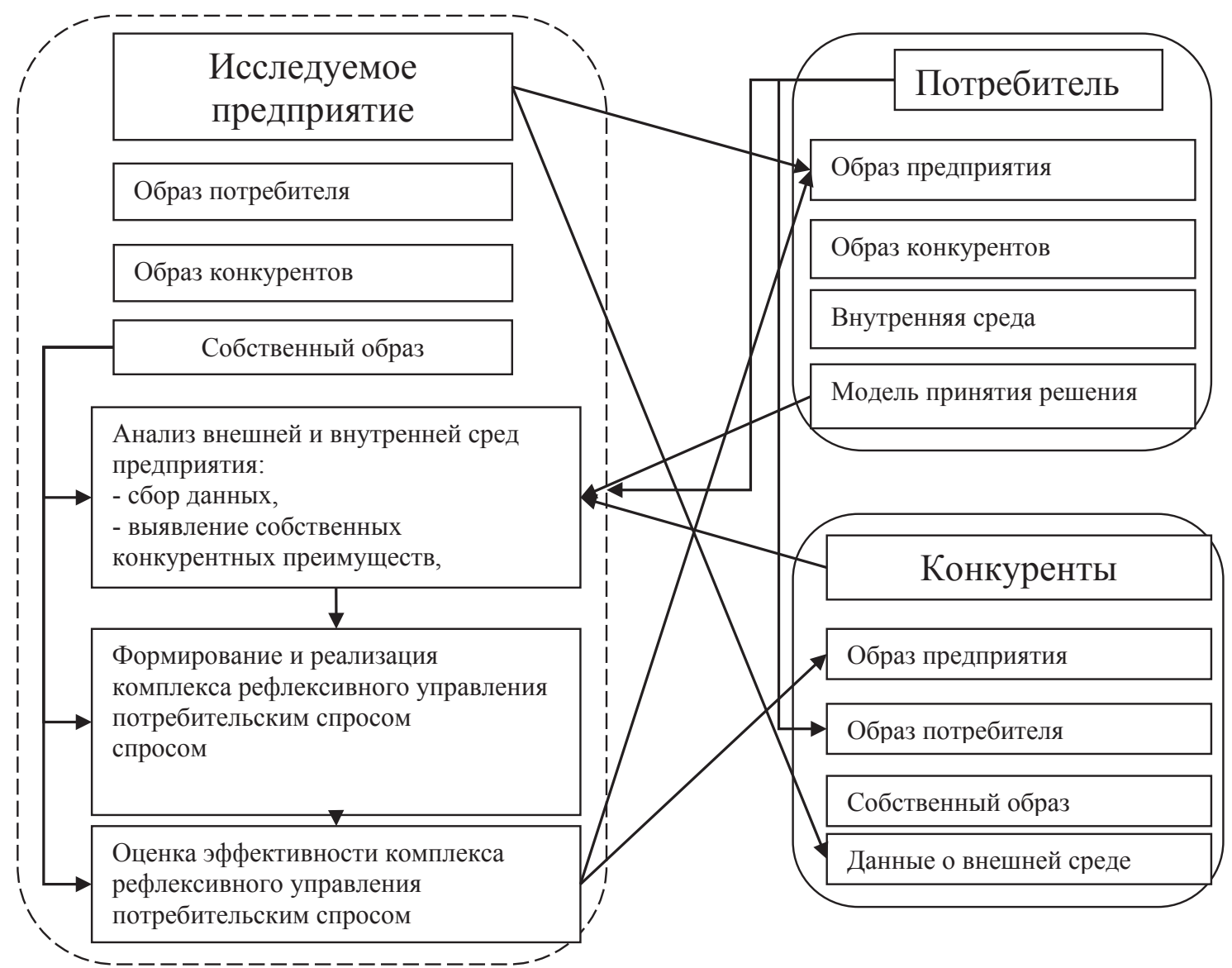

Рис. 6. Концепция рефмексивного управмения потребительским спросом

Выводы после приобретения товара/ускуги повлияют на Аальнейшее отношение потребитемя к проАавцу. Таким образом, покупатель оценивает проАукт как уАовлетворяющий или нет. При ощущении полного УАовлетворения от покупки, кАиент приобретает положительный опыт, который в Аальнейшем становиться частью внутреннего источника информации и будет оказывать влияние на второй и третий этапы процесса принятия решения. При негативном опыте из-за отсутствия удовлетворения потребности происходит отказ клиента от товаров/ускуг проАавца и последующим поиском Аругих альтернатив.

На основе рассмотренных этапов выбора потребитемя и использования теории рефлексии В.А. Аефевра составим концепцию рефмексивного управления потребительским спросом (рис. 6). В Аанной концепции рефлексивного управления потребитемьским спросом схематично разделены участники экономических взаимоотношений на три группы: исслеАуемое коммерческое преАприятие, потребитель и конкуренты. Использование Аанного разделения необходимо Аля того что бы показать возможные отличия в истинном состоянии субъекта взаимоотношений и его преАставлений о себе в сложившейся ситуации. Модель рефлексивного управления будет состоять из трёх последовательных этапов: анациз
Аанных, формирование и реализация комплекса ре $\phi-$ мексивного управцения, и оценка эффективности применения (рис. 6).

На первом этапе происходит сбор и обработка Аанных о внешней и внутренней среАах, в которых функционирует исследуемое преАприятие. Осуществляется анализ рыночных возможностей, отбор целевых рынков, сегментирование потребителей, группировка конкурентов по значимым признакам Аля потребителя. Особое внимание необходимо УАелить расчёту параметра потребительской привлекательности как Аля преАприятия самого, так и его основных конкурентов, потому что на основе Аанных качественных оценок можно сАелать заключение о вероятности посещения того или иного торгового объекта цемевыми покупателями.

На втором этапе происходит формирование комплекса рефмексивного управления и его реализация, используя инструментарий рефмексивных игр В.А. Аефевра аля выявления эффективных направмений действий коммерческого преАприятия. Модемирование плацдарма взаимоотношений и влияний экономических агентов Ааст возможность рассчитать вероятность совершения покупки целевыми потребителями. А на основе этого показателя и наличия Аанных о количестве населения в исслеАу- 
емых торговых зонах и их среднем уровне трат на исследуемую группу товаров, появляется возможность моделирования функции спроса и вычисления возможной прибыли, что в свою очереАь позволяет перейти к третьему этапу моделирования. Таким образом, оценка эффективности рассчитывается на основании функциональной зависимости спроса от вероятности посещения потребителями исследуемого коммерческого преАприятия.

\section{4. Выводы}

Развитие рефлексивного управления применительно к экономике предстаёт в виде целенаправменной организации рефмексивных воздействий на управляемый субъект с целью склонения его к принятию решений, прогнозируемых управляющей системой. Что в свою очередь снижает неопределённость и создаёт преимущества Аля управмяющей стороны.
Научная новизна полученных результатов состоит в развитии концепции рефмексивного управления потребительским спросом, которая позволяет учитывать мичные преАпочтения потенциальных кииентов в Аеятельности коммерческого преАприятия. Концепция предусматривает использование на практике цеменаправленных воздействий на информационные каналы потребителей и способствует обеспечению конкурентных преимуществ торговой точки неценовыми методами в условиях нестабильной рыночной среды. Усовершенствовано модель процесса принятия потребителем решения о покупке, учитывающая, в отличие от существующих моделей, цикличность процесса выбора, различные сценарии поведения и мичные предпочтения целевого потребителя. Все это позволяет определить ключевые этапы процесса принятия решения потребителем с целью разработки комплекса рефлексивных воздействий.

\section{References:}

Lefevre, V.A. (2009). Lectures on the theory of reflexive games. Moscow: Cogito-Centre, 89-103.

Lefevre, V.A. (2003). Reflexion. Moscow: Cogito-Centre, p. 17-20.

Lepa, R.N. (2012). Models of reflexive management in the economy. Donetsk: Institute of Industrial Economics, p. 54-77.

Levy, M., Weitz, B.A., Grewal, D. (2013). Retailing Management. McGraw-Hill Companies, Inc., p. 83-107.

Kotler, P. (1984). Marketing Essentials. Englewood: Prentice-Hall, Inc., p. 45-47.

Yadgarov, Y.S. (2009). History of Economic Thought. Moscow: Publishing House "INFRA-M", p. 104-117, 272-329.

\section{Марина МАВРИНА}

\section{КОНЦЕПЦИЯ РЕФЛЕКСИВНОГО УПРАВЛЕНИЯ ПОТРЕБИТЕЛЬСКИМ СПРОСОМ}

Аннотация. Развитие теоретических подходов управления спросом ведутся с момента осознания представителями экономической науки важности данного понятия. С усложнением теоретических подходов к анализу экономического поведения с точки зрения психологической природы человека было разработано множество моделей индивидуальных потребителей. Однако для прогнозирования реакции потребителей на коммерческую политику предприятия в условиях не ценовой конкуренции точных методов пока не существует, потому что имеющиеся носят преимущественно эмпирический характер. Так же необходимо признать, что используемые модели поведения часто не обеспечивают ожидаемый результат по причине ошибочного подхода к анализу механизма формирования спроса как такового. Предметом исследования выступают теоретико-методические основы, методы оценки и рефлексивного управления потребительским спросом коммерческих предприятий. Целью исследования является разработка концепции рефлексивного управления потребительским спросом. Для достижения цели исследования поставлены и решены такие задачи: обосновать теоретико-методологические основы рефлексивного управления потребительским спросом, выявить и проанализировать существующие подходы к моделированию потребительского поведения; усовершенствовать модель потребительского поведения; разработать концептуальные положения рефлексивного управления поведением потребителей. Методика. В работе использованы такие методы и подходы к исследованию: рефлексивный подход (феноменологический метод), поведенческая экономическая теория, маркетинговый подход, абстрактно-логический анализ использованы при исследовании теоретико-методологических основ управления взаимодействиями, анализе теоретических подходов к моделированию потребительского поведения, разработка концепции рефлексивного управления поведением потребителя, при теоретическом обобщении и формулировании выводов. Результаты. Имеющиеся в настоящее время подходы к моделированию потребительского поведения носят преимущественно эмпирический характер и обладают недостатками общих моделей. В них нет описания 
конкретныхпокупательских ситуаций настолько подробно, чтобы быть практическими моделями, и их нельзя выразить количественно. Несмотря на это проанализированные в данной работе подходы имеют весомое преимущество во всестороннем взгляде на мотивированные покупки, что позволяет оценить релевантность отдельных переменных и тем самым лучше понять фундаментальные процессы поведения потребителей. Делает возможным идентифицировать необходимые для исследования переменные, даёт старт для построения гипотезы и точки отсчёта для интерпретации результатов экспериментов. Практическоезначение и оригинальность полученных результатов состоит в развитии концепции рефлексивного управления потребительским спросом, которая позволяет учитывать личные предпочтения потенциальных клиентов в деятельности коммерческого предприятия. Концепция предусматривает использование на практике целенаправленных воздействий на информационные каналы потребителей и способствует обеспечению конкурентных преимуществ торговой точки неценовыми методами в условиях нестабильной рыночной среды. Усовершенствовано модель процесса принятия потребителем решения о покупке, учитывающая личные предпочтения целевого потребителя. Все это позволяет определить ключевые этапы процесса принятия решения потребителем с целью разработки комплекса рефлексивных воздействий. 